EPiC Series in Engineering
Volume 3, 2018, Pages 2393-2398
HIC 2018. 13th International
Conference on Hydroinformatics

\title{
Application System for Integrated Water and Water Environment Management in The Hai River Basin
}

\author{
Guiyu Yang ${ }^{1 *}$, Hao Wang ${ }^{1}$, Yangwen Jia ${ }^{1}$, Xiaohui Lei ${ }^{1}$, Weiwei Shao ${ }^{1}$ and \\ Zhaohui Yang ${ }^{1}$ \\ ${ }^{1}$ China Institute of Water Resourcs and Hydropower Research, Beijing, China \\ guiyuy@iwhr.com
}

\begin{abstract}
With the rapid increasing of economy and population, water resources shortage and a series of water-related eco-environmental issues has pain attention in the worldwide. The related issues is more distinct in the Hai River Basin. To realize the integrate management for the water and environment, the application system were developed in the Basin-scale. The application system includes the following three parts: the dualistic core model, the theme database system and the business management system. The dualistic model, as the core part in the system, provided the long-term planning management by the scenario analysis of the natural-social water cycle process. The business management system mainly serviced for the daily business management work including data inquire, statistics and analysis from the theme database information. The theme database system collects lots of information that from the dualistic model simulation results, the monitoring and statistics information of the whole "natural-social "water cycle process in practice. The system carried out a good support for the stringency water resources management in Hai River Basin
\end{abstract}

\section{Introduction}

With the rapid increasing of economy and population, water resources shortage and a series of water-related eco-environmental issues have pain attention in the worldwide. In the Hai River Basin, due to the poor natural water resources conditions, together with the influence of the high intensity human activity and the global climate change, the shortage of water resources and its associated ecological and environmental problems have become more severe. The eco-environmental issues including the depleted channel, shrinkage lake and over-exploitation groundwater, and so on had been

${ }^{*}$ Corresponding author 
appeared since the 1980s. To improve the situation and realize the completely manage for water resources and environment, since 2007, together supported by the global environment fund project (alleviated as GEF) (Beijing IWHR Engineering Corporation \&Tsinghua University ,2011) and the other projects, the application system for the integrated water and environment was developed based on the "natural-social" dualistic water cycle characteristic. The application system consists of the theme database system, the dualistic model and business management system. The dualistic model, as a core part, may relative acutely simulate to the transformation of the water elements based on the hydrological cycle units of 11752 and 454 management units of legend covering water-resources region. In addition, the simulation results may provide direction for the rational development and utilization of the water resources. Based on the data mining to lot data form the theme database and dualistic module results, the business management system has the function as following: data inquire, the evolution rule analysis of water and that of environment, and so on. In general, the integrated management system has support well supported for daily business management and long-term make-decision of water resources and water environment. The theme database provides plenty of data and information supporting the dualistic model and the business management system

The paper is structured as follows: after this introduction, section 2 describes the water resources and environment situation in study area, and the basic theory and methods supporting the development of the integrate management system; Section 3 presents the structure of the integrate management system and its application in the Hai River Basin; The final section carries out the conclusion and discussions after the scenarios simulation and water cycle element analysis base on the application system.

\section{Materials and Methods}

\subsection{Study Area}

The Hai River Basin is located in eastern China between $112^{\circ} \mathrm{E}-120^{\circ} \mathrm{E}$ and $35^{\circ} \mathrm{N}-43^{\circ} \mathrm{N}$, covers Beijing, Tianjin, Hebei and five other provinces (including autonomous regions and municipalities), and has a total area of $320,000 \mathrm{~km} 2$, accounting for $3.3 \%$ of the total national area. The total population in the basin reached $1.45 \times 108$ in 2015 , accounting for $10.9 \%$ of the national population; and the gross domestic product (GDP) reached $6.9 \times 108$ yuan, accounting for $13 \%$ of the national GDP. The irrigation area reached $550 \times 104 \mathrm{ha}$, accounting for $8.0 \%$ of the national irrigation area. However, there is little optimism for the basin's natural water resources condition. With the increasing uncertainty of natural precipitation under the condition of the effects of global climate change, the water resources situation will confront with more and more serious. At the same time, under the high intensity human activity, the amount of water utilization has increasing tendency. The above two aspects cause to the imbalance between supply of water resources and their demand.

Therefore, in view of the clear "natural-social" dualistic water cycle characteristics with climate changes and high-intensity human activities, it is significant for the integrated water and environment management to build an application system based on the natural-social water cycle theory.

\subsection{Methods}

The Natural hydrology is a transform process among the four kinds of water element including precipitation, surface water, and soil water, as well as groundwater driver by solar energy and gravity. With the daily intensity human activity, the social lateral cycle with "supply-usage-drainage-reuse" subprocess plays an important role in the whole water cycle process, and affects the conflux and runoff product in the natural hydrology process. 
To revolve the evolution character of the water cycle, and sustainable use in practice, the mechanism model and the statistics method were employed in the application system. In which, the mechanism model, namely the dualistic model, was established based on the four-water transform mechanism associated to the artificial water resources allocation. The statistics methods mainly include the tendency, period analysis methods, and figure and table.

\section{The System Introduce and Its Application}

\subsection{The Application system Structure and Its Basic Function}

The structure of the application system shown in figure 2. It can be seen that the dualistic model lied in the core place. The theme database system plays a basic function. The business management system lies in the top, directly faces to different user based on the supporting of the dualistic model and the theme database system.

The dualistic model, called as the core model, was capable to coupling simulation of surface and groundwater, natural hydrological processes and artificial water cycle processes, and water quantity and quality by considering all the factors of natural evolution, intensive human activities and urbanization, controlling effects of water resources works, etc. The dualistic model consisted of the water cycle model, water resources allocation module and the macro-scale economy module. Jointing the three modules, the dualistic module may simulate the different water-used scenario; further give rational advice to governor by comparing to the different simulation results. The detail information of the dualistic model may referent to literature (Yangwen Jia, et al. 2010).

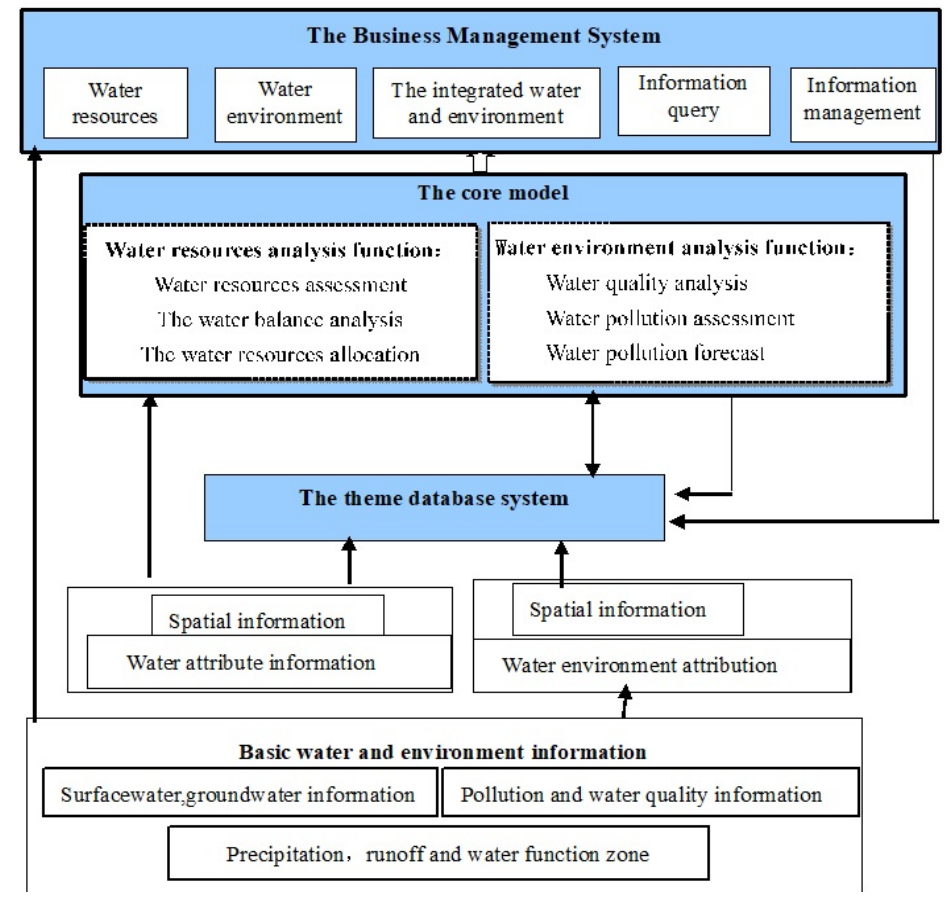

Figure 1: The Structure of The Application System 
The business management system was oriented in a service platform to all level user. The system may provide not only some information of water and environment but also supply the basic function including query, statistics and analysis. In addition, Analysis and assessment module in the system consists of three parts: water resources analysis and assessment system, water environment analysis and assessment system and integrated water resources and water environment analysis and assessment system. It mainly uses the analysis and calculation method to analyse, deeply estimate, and reasonably forecast water resources and water environment information.

The theme database system, as a basic part in the system, may provide lots data information, which from the dualistic model simulation results, and the basic statistics information in practice. In addition, the theme system also provide data support to the dualistic model and the business management system. The detail establish environment and the total structure shown the reference (Suhua, Han ,2009)).

\subsection{The Application of The system in Hai River Basin}

To provide the different level management requirement, the application system divided the whole basin covering 8 administrative regions into 4 second-level water resources zones and 15 third-level water resources zones. In addition, one-level water environment function zone with 25 protect subzones, 23 reserve subzones, and 194 development-utilization subzones, as well as alleviated subzone also was contained in the application system in order to well protect the water environment.

Based the above-statement spatial units, the natural-artificial water cycle elements and its associated with the water environment elements were stored in the different database systems by collecting monitoring information and calculating information. In which, the monitoring database system mainly store the meteorological data including the precipitation, evapotranspiration, groundwater level, river flow amount and so on, which may provide the daily water management analysis and also is the dualistic core model basic information. The theme system was used to store the water amount data, water environmental data and water-environmental management information according to water resources management sub-theme system, water environmental management sub-theme system and the waterenvironmental management sub-theme system. The data and the relative information provide well support for the daily management and the core dualistic model calculation.

The core dualistic model is abbreviated for the Dualistic Water and Environment Management Model (DWEMM). The model couplings the WEP distributed hydrological module, Rules-based Objected-oriented Water Allocation Simulation Module (ROWAS) and Decision Analysis for Multiobjective System (DAMOS) module. In which, DAMOS module is a comprehensive mathematical model restraints mechanisms between several sub-systems including society, economy, environment, water resource, etc. and each inside are highly summarized. Meanwhile, the module describes assignment relations of capital and resource in every sub-system belonging to complex giant system 'economy-environment-society-resource-ecology', and the harmony of these relations and society development mode. Considering the obtaining of the social-economical information, the module was implemented in the province spatial units. ROWAS module places in the linking status between DAMOS module and WEP module. Through rational allocation of water resources, macro decisionmaking objectives of DAMOS are rationally distributed both in time and space and the rationality is tested based on the water resources zones. The WEP module, the lowest layer in the core model, is used to fine simulate natural-artificial dualistic water cycle process considering many elements, such as the regional land use sorts, water utilization situation, water amount and quality at the important section at river and provincial boundary, water amount flowing into Bohai Sea and contamination control. The minimum calculation unit with 3067 sub-basins and 11752 calculated units is included in the WEP modules. The relation map of the coupling of the three modules shown in figure 2 .

Under the support of the database system and the core dualistic model, based-ET management was carried by the current water utilization and planning scenarios simulation. Under the objective ET constrain, the application gives the rational groundwater exploitation value, the surface water usage and 
the inflow and outflow in the different water resources districts in Hai River basin. The relative information well support the water resources requirement management. At the same time, based on history and current water quantity both inflow and outflow as well as basic data of pollutant amounts, the core model provides simulating and analyzing data as the main boundary conditions. The relative study results were significant to the water ecological restoration and the total amount control of pollutants. The table 2 gives the water resources utilization and controlling amount in the 2030 planning level year according to the basic water resources condition and the available water resources amount shown in table 1

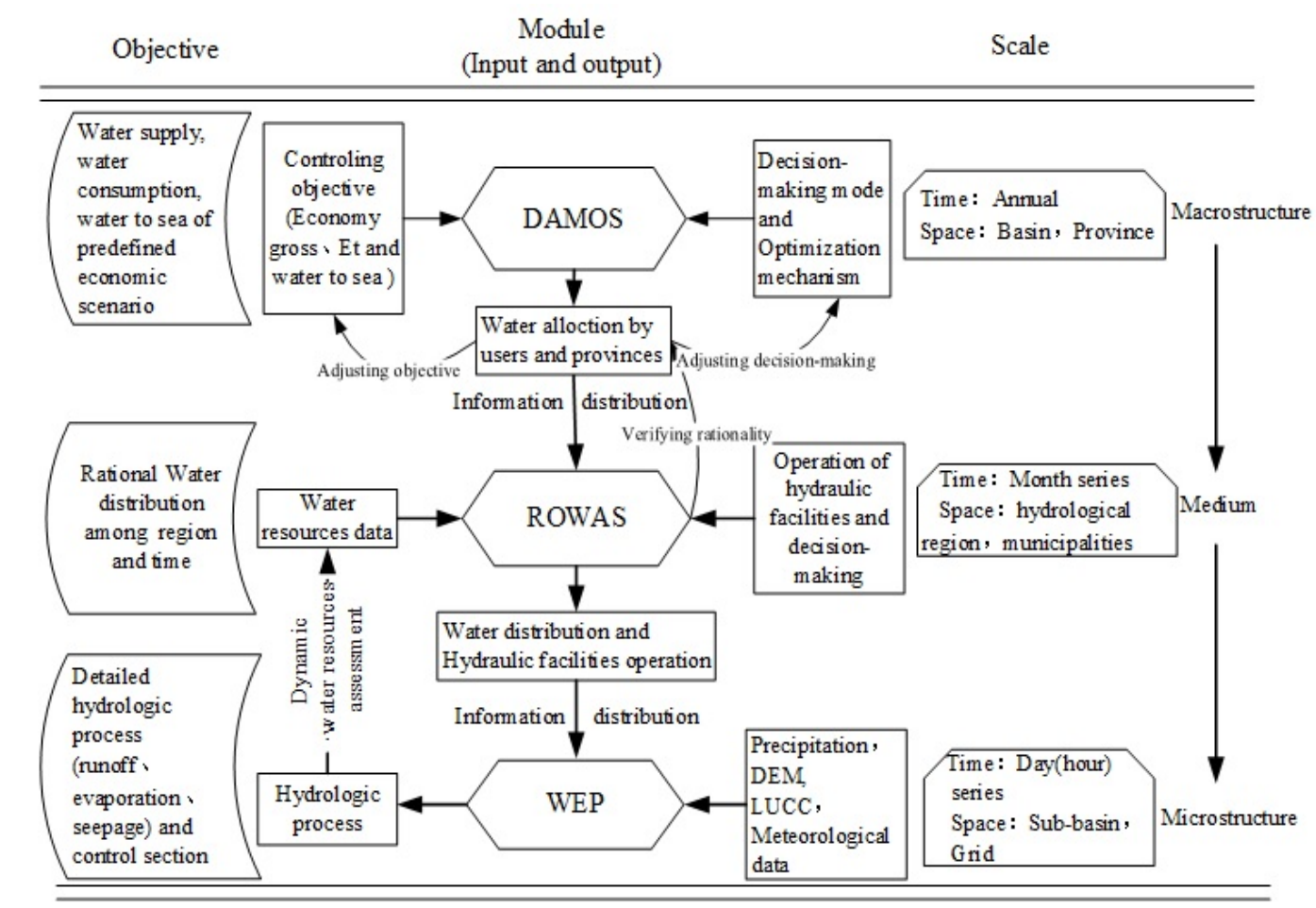

Figure 2: Relation Map of The Coupling among The Three Module

Table 1: Scenarios of Water Quantity Control

Unit: $10^{\wedge} \mathrm{m}^{3}$

\begin{tabular}{|c|c|c|c|c|c|c|}
\hline \multirow{2}{*}{$\begin{array}{l}\text { Level } \\
\text { year }\end{array}$} & \multirow{2}{*}{$\begin{array}{l}\text { Precipi } \\
\text { tation }\end{array}$} & \multirow{2}{*}{$\begin{array}{l}\text { Over- } \\
\text { exploitation of } \\
\text { groundwater }\end{array}$} & \multirow{2}{*}{$\begin{array}{l}\text { Water } \\
\text { amount to } \\
\text { Sea }\end{array}$} & \multicolumn{2}{|c|}{$\begin{array}{l}\text { South-to-North Water } \\
\text { Diversion }\end{array}$} & \multirow{2}{*}{$\begin{array}{c}\text { Water } \\
\text { diverted } \\
\text { from Yellow } \\
\text { River }\end{array}$} \\
\hline & & & & Mid-route & $\begin{array}{l}\text { East- } \\
\text { route }\end{array}$ & \\
\hline 2030 & 1596.2 & 0 & 93 & 83.9 & 31.3 & 43.3 \\
\hline
\end{tabular}

The specific water resources condition in 2030 planning level year shown in table 1 is as following: groundwater overexploitation is zero; South-to-North water diversion (from the Yangtze River) is the twice-stage full diversion ability of the two routes with the diversion amount of $114.2 \times 108 \mathrm{~m} 3$. In addition, the water diverted from Yellow River also should be water transfer of $43.3 \times 108 \mathrm{~m} 3$.at the same time, the amount of the water flowing into Sea should be $93 \times 108 \mathrm{~m} 3$ (that is he average value of the water flowing into sea from 1956 to 2005). 
Under the above-statement the water resources condition, the results (seen in table 2) shows that the maximum available consumption of water resources in the whole basin should be maintained in $1685 \times 108 \mathrm{~m} 3$ in 2030 year under the drought hydrological situation. In which, the national economy use of $411 \times 108 \mathrm{~m} 3$, and the artificial eco-environment water use of $20.9 \times 108 \mathrm{~m} 3$ should be constrained in 2030 year. Meanwhile, the amount of groundwater exploitation should be controlled below $172 \times 108$ $\mathrm{m} 3$, and the amount of the surface fetched water should be $260 \times 108 \mathrm{~m} 3$. The code in the table 2 means that: OEG indicated as groundwater overexploitation; SWD indicated surface water drawing; NEU indicated national economy use; EEU indicated the eco-environment use; and WFS indicated water flowing to sea.

Table 2: The Controlling Indices in The Hai River Basin in 2030 Level Yea

Unit: $10^{\wedge} \mathrm{m}^{3}$

\begin{tabular}{ccrrrrr}
\hline $\begin{array}{c}\text { Level } \\
\text { year }\end{array}$ & $\begin{array}{l}E T_{m a} \\
x\end{array}$ & $\begin{array}{c}\text { the OEG } \\
\text { Amount }^{*}\end{array}$ & $\begin{array}{c}\text { the SWD } \\
\text { Amount }^{*}\end{array}$ & $\begin{array}{c}\text { the } \\
\text { NEU } \\
\text { Amount }\end{array}$ & $\begin{array}{c}\text { the } \\
\text { EEU } \\
\text { Amount }^{*}\end{array}$ & $\begin{array}{c}\text { the } \\
\text { WFS } \\
\text { Amount }^{*}\end{array}$ \\
\hline 2030 & 1685 & 171.9 & 260.2 & 410.9 & 20.9 & 86.4
\end{tabular}

\section{Conclusion and Discussion}

The application system for the integrated water and environment management is applied in the process of the GEF project from 2007 to 2012, and also supported in the stringency water resources. The application system gives the following results: the elements of the water balance, the water quality situation in the main section in the river, and the total amount controlling indicators based on the Hai River Basin Commission management object. At the same time, the evolution process of the water cycle elements also may be given. In general, the system provides to support not only the strategic study and strategic active planning in GEF project from 2007 to 2012, but also the establishment of the three lines reds in the stringent water resources in the whole basin. The application in 2030 planning level year as an example directly reflects the system function. However, the appliance for the long term should improve the application system improved associated with the changing of the development of the water resource and environment protection.

\section{References}

Beijing IWHR Engineering Corporation \&Tsinghua University (2011).Application System for Integrated Water and Environment Planning and Management in the Hai Basin(Technology report)

Yangwen Jia, Hao Wang, Zuhao Zhou,et al. (2010). Development and application of dualistic water cycle model in Haihe River Basin: I. Model development and validation. Advances in Water Science, Vol.21 No.1,1-8.

Suhua Han, Xiaohui Lei, Yu Tian, et al(2009). The development of the theme database. GEF dissertation. pp451-500 